\title{
The Effects of Age, Endometriosis, Polycystic Ovarium Syndrome, and Obesity on the Success of Embryo Transfer on In Vitro Fertilization
}

\author{
Atthahira Amalia Hafiizha, ${ }^{1,2)}$, Uki Retno Budihastuti3), Bhisma Murti2) \\ 1)Faculty of Medicine, Universitas Sebelas Maret \\ 2)Masters Program in Public Health, Universitas Sebelas Maret \\ 3) Department of Obstetrics and Gynecology, Faculty of Medicine, \\ Universitas Sebelas Maret/ Dr. Moewardi Hospital, Surakarta
}

\section{ABSTRACT}

Background: One of the important stages in in vitro fertilization (IVF) success is the embryo transfer (ET). Many studies are examining the effect of maternal factors on in vitro fertilization outcomes. However, studies that are only up to the ET stage are still rare. This study aimed to prove whether maternal factors, especially age, endometriosis, PCOS, and obesity, affect ET success in IVF.

Subjects and Method: This was an analytic observational study with a case-control design. A sample of 111 patients who undergo IVF at Sekar Fertility Clinic, Dr. Moewardi Surakarta, was selected by total sampling. The dependent variable was the ET success. The independent variables were maternal age, history of endometriosis, PCOS, and obesity. The data were analyzed by a multiple logistic regression.

Results: The prevalence of ET success in IVF from January 2014 to November 2019 at Sekar Fertility Clinic, Dr. Moewardi, was 65.77\% (73 of 111 cycles). Only a history of endometriosis could affect the ET success which was statistically significant $(\mathrm{aOR}=0.25 ; 95 \% \mathrm{CI}=0.08$ to $0.78 ; \mathrm{p}=0.017)$. ET success was affected by age, PCOS, and obesity, but it was not statistically significant.

Conclusion: Endometriosis affects the ET success in IVF, and it is statistically significant. While age, PCOS, and obesity affect the ET success in IVF, but they are not statistically significant.

Keywords: embryo transfer, in vitro fertilization, endometriosis, polycystic ovarium syndrome

\section{Correspondence:}

Atthahira Amalia Hafiizha. Faculty of Medicine, Universitas Sebelas Maret. Jl. Ir. Sutami 36A, Surakarta 57126, Central Java. Email: atthahira1410@gmail.com.

Cite this as:

Hafiizha AA, Budihastuti UR, Murti B (2021). The Effects of Age, Endometriosis, Polycystic Ovarium Syndrome, and Obesity on the Success of Embryo Transfer on In Vitro Fertilization. J Matern Child Health. 06(02): 146-153. https://doi.org/10.26911/thejmch.2021.06.02.02

cc) (i) (2) Journal of Maternal and Child Health is licensed under a Creative Commons Attribution-NonCommercial-ShareAlike 4.o International License.

\section{BACKGROUND}

Infertility is a term that describes when husband and wife are unable to achieve pregnancy (clinical pregnancy) after at least 1 year of having regular sexual intercourse without contraception (Zegers-Hochschild et al., 2009). One procedure that couples can do to have children is in vitro fertilization (IVF). IVF is a type of Assisted Repro- duction Technology (ART). In Indonesia, the ART procedure cases, especially IVF in 2017, were 9122 cycles (IAIVF, 2017).

The ET stage in IVF is important in the IVF success, which is still received little attention (Niederberger, 2018). One of the problems in IVF is the failure to transfer embryos. Based on data from the Indonesian Association for In Vitro Fertilization 
(IAIVF) in 2017, there were 1460 in vitro fertilization cycles that experienced the cancellation of the embryo transfer stage (IAIVF, 2017). There have been many studies examining the correlation between maternal factors and IVF outcome. However, studies that are only up to the embryo transfer phase are still rare. Therefore, researchers are interested in conducting the study on the effect of age, endometriosis, Polycystic Ovary Syndrome (PCOS), and obesity in mothers on the ET success in IVF to find out whether these maternal factors have an effect on ET or not so that the IVF success can be optimal.

\section{SUBJECTS AND METHOD \\ 1. Study Design}

This was an analytic observational study with a case-control design. The study was conducted at Sekar Fertility Clinic, Dr. Moewardi Hospital, Surakarta, Ccentral Java, from October to November.

\section{Population dan Sample}

The accessible population was patients who underwent IVF procedures at Sekar Fertility Clinic, Dr. Moewardi Hospital, from 2014 to 2019. A sample of 111 women was selected by total sampling.

\section{Study Variables}

The dependent variable was the ET success. The independent variables were maternal age, history of endometriosis, PCOS, and obesity.

\section{Operational Definition of Variables Embryo transfer (ET) was a procedure} in which a number of embryos are placed into the uterus or fallopian tubes. Embryos of good or sufficient quality are transferred. Age was the length of time of life or existence (since birth). Age could be seen from the data on the date of birth of the study subject. The data obtained were continuous data and converted into a dichotomy, $<40$ years and $\geq 40$ years.
Endometriosis was a condition in which the endometrial glands and stroma functioning were outside the uterine cavity (Prawirohardjo, 2014). The data obtained were categorical.

PCOS (Polycystic Ovary Syndrome) or polycystic ovary syndrome was an endocrine disorder which was generally characterized by irregular menstruation, hyperandrogenism, and polycystic ovaries (Sirmans and Pate, 2014). The data obtained were categorical data.

Obesity was a disorder of excessive fat accumulation that can interfere with health. Obesity could be seen by calculating the patient's BMI. BMI $\geq 25$ was considered obese. Obesity data obtained were continous data.

\section{Data Analysis}

Data were analyzed by bivariate using chisquare analysis and multivariate logistic regression analysis to see the effect of age, endometriosis, PCOS, and obesity in mothers on the ET success by IVF.

\section{Research Ethics}

Ethical eligibility was obtained from the Health Research Ethics Commission of Dr. Moewardi, Surakarta, Indonesia, with number: 1.15O/X/HREC/2019.

\section{Sample Characteristics}

In this study, the samples obtained were 111 cycles from 97 study subjects with the sampling method in the form of total sampling. The prevalence of ET success from January 2014 to November 2019 at Dr. Moewardi Regional Public Hospital was $65.77 \%$ (73 out of 111 cycles). The results of this study indicated that patients aged less than 40 years (69.6\%) had a higher ET success than patients aged 40 years and over $(47.4 \%)$. 
Hafiizha et al./ the Success of Embryo Transfer on In Vitro Fertilization

Table 1. Sample Characteristics

\begin{tabular}{lcc}
\hline \multirow{2}{*}{ Characteristics } & \multicolumn{2}{c}{ Embryo Transfer } \\
\cline { 2 - 3 } & $\begin{array}{c}\text { Unsuccessful } \\
\text { n (\%) }\end{array}$ & $\begin{array}{c}\text { Successful } \\
\text { n (\%) }\end{array}$ \\
\hline Age & $28(30.4)$ & $64(69.6)$ \\
$<$ 40 years & $10(52.6)$ & $9(47.4)$ \\
$\begin{array}{l}\text { 40 years } \\
\text { Endometriosis }\end{array}$ No & $27(28.7)$ & $67(71.3)$ \\
Yes & $11(64.7)$ & $6(35.3)$ \\
PCOS & & \\
No & $36(37.9)$ & $59(62.1)$ \\
Yes & $2(12.5)$ & $14(87.5)$ \\
Obesity & & \\
BMI $<25$ & $28(40.0)$ & $42(60.0)$ \\
BMI $\geq 25$ & $10(24.4)$ & $31(75.6)$ \\
\hline
\end{tabular}

This study also showed that the patients who did not have a history of endometriosis (71.3\%) had a higher ET success rate than those with a history of endometriosis (35.3\%). Meanwhile, for patients who had a history of PCOS (87.5\%), the ET success rate was higher than those without PCOS history (62.1\%). Likewise, mothers with a BMI of less than 5 (60.0\%) had a lower ET success rate than those with a 25 and over (75.6\%). The complete distribution of the characteristics of study subjects can be seen in Table 1 .

\section{Bivariate Analysis}

Table 2 shows that the existence of a history of endometriosis significantly affects the ET success in IVF. Mothers with a history of endometriosis had a 0.22 times more ET success than those without a history of endometriosis $(\mathrm{OR}=0.22 ; 95 \% \mathrm{CI}=0.07$ $0.65 ; \mathrm{p}=0.009$ )

In this study, it was found that age, history of PCOS, and obesity in mothers did not significantly affect the ET success in IVF. Based on the chi-square test, it showed that age had no significant effect on the ET success $(\mathrm{OR}=0.39 ; 95 \% \mathrm{CI}=0.14-1.08 ; \mathrm{p}=$ 0.112). The history of PCOS based on chisquare test showed no significant effect on the ET success $(\mathrm{OR}=4.27 ; 95 \% \mathrm{CI}=0.92-$
19.89; $\mathrm{p}=$ 0.090). Likewise, obesity (BMI 225) did not significantly affect the ET success $(\mathrm{OR}=2.07 ; 95 \% \mathrm{CI}=0.88$ to 4.88 ; $\mathrm{p}=0.143)$.

\section{Multivariate Analysis}

Table 3 shows that the multivariate analysis table showed the maternal factors most significantly affected the ET success in IVF was a history of endometriosis. Mothers with a history of endometriosis were 0.25 times more likely to successfully transfer embryos than those without a history of endometriosis $(\mathrm{OR}=0.25 ; 95 \% \mathrm{CI}=0.08$ $0.78 ; \mathrm{p}=0.017)$.

In this study, age, history of PCOS, and maternal obesity had no significant effect on the ET success IVF. Based on the logistic regression analysis test, it showed that age did not have a significant effect on ET success. Mothers with age $\geq 40$ had a 0.44 times chance of ET success than those aged $<40$ years $(\mathrm{OR}=0.44 ; 95 \% \mathrm{CI}=0.15$ 1.28; $\mathrm{p}=0.133)$.

The history of PCOS in the mother based on logistic regression analysis showed no significant effect on the ET success. Mothers with a history of PCOS had a 2.5 times chance of ET success compared to those without a history of $\mathrm{PCOS}(\mathrm{OR}=2.51 ; 95 \% \mathrm{CI}=0.51$ to $12.31 ; \mathrm{p}=$ 
Hafiizha et al./ the Success of Embryo Transfer on In Vitro Fertilization

0.257).

Likewise, obesity (BMI $\geq 25$ ) did not significantly affect ET success. Obese mothers were 1.65 times more likely to

Table 2. The results of the bivariate analysis of factors affecting the ET success on IVF

\begin{tabular}{|c|c|c|c|c|c|c|}
\hline \multirow{3}{*}{$\begin{array}{c}\text { Independent } \\
\text { Variable }\end{array}$} & \multicolumn{4}{|c|}{ Embryo Transfer } & \multirow{3}{*}{ OR (CI 95\%) } & \multirow{3}{*}{$\mathbf{p}$} \\
\hline & \multicolumn{2}{|c|}{ Unsuccessful } & \multicolumn{2}{|c|}{ Successful } & & \\
\hline & $\mathbf{n}$ & $\%$ & $\mathbf{n}$ & $\%$ & & \\
\hline \multicolumn{7}{|l|}{ Endometriosis } \\
\hline No & 27 & 28.7 & 67 & 71.3 & \multirow{3}{*}{$\begin{array}{c}0.22 \\
(0.07-0.65)\end{array}$} & \multirow[t]{3}{*}{0.009} \\
\hline Yes & 11 & 64.7 & 6 & 35.3 & & \\
\hline Obesity & & & & & & \\
\hline $\mathrm{BMI}<25$ & 28 & 40.0 & 42 & 60.0 & \multirow{2}{*}{$\begin{array}{c}2.07 \\
(0.88-4.88)\end{array}$} & \multirow[t]{2}{*}{0.143} \\
\hline $\begin{array}{l}\mathrm{BMI} \geq 25 \\
\mathbf{P C O S}\end{array}$ & 10 & 24.4 & 31 & 75.6 & & \\
\hline No & 36 & 37.9 & 59 & 62.1 & 4.27 & \multirow[t]{2}{*}{0.090} \\
\hline Yes & 2 & 12.5 & 14 & 87.5 & $(0.92-19.89)$ & \\
\hline
\end{tabular}

Table 3. The results of multiple logistic regression analysis of factors affecting ET success on IVF

\begin{tabular}{lcccc}
\hline \multirow{2}{*}{ Independent Variable } & \multirow{2}{*}{ OR } & \multicolumn{2}{c}{$\mathbf{9 5 \%}$ CI } & \multirow{2}{*}{ p } \\
\cline { 3 - 4 } & & Lower limit & Upper limit & \\
\hline Age $(\geq$ 40 years) & 0.44 & 0.15 & 1.28 & 0.133 \\
Endometriosis & 0.25 & 0.08 & 0.78 & 0.017 \\
PCOS & 2.51 & 0.51 & 12.31 & 0.257 \\
Obesity (IMT $\geq 25)$ & 1.65 & 0.67 & 4.10 & 0.277 \\
Constanta & 2.15 & - & - & 0.016 \\
n observation = 111 & & & & \\
Nagelkerke R2 $=16.8 \%$ & & & \\
-2 Log likelihood = 128.27 & & & \\
\hline
\end{tabular}

\section{DISCUSSION}

1. Characteristics of Study Subjects

The prevalence of ET success from January 2014 to November 2019 was found at Dr. Moewardi was $65.77 \%$ (73 of 111 cycles). These data on the prevalence of ET success show a difference compared to other studies.

In a study conducted by $\mathrm{Ji}$ et al. (2013), the prevalence of ET success was 86.03\%, higher than this study. A study conducted by Tan et al. (2014) also showed that the prevalence of ET success was $93.76 \%$ (3199 out of 3412 cycles). A difference in the prevalence rate of ET success in this study with other studies is possible succeed at embryo transfer than those who were not obese $(\mathrm{OR}=1.65 ; 95 \% \mathrm{CI}=0.67$ $4.10 ; p=0.277)$. 
ET is due to early luteinization, no ovarian response, no oocytes during the oocyte collection phase, and not fertilized.

A study conducted by Tan et al. (2014) also showed that age had a significant effect on ET success $(p<0.001)$. The study was conducted using retrospective analysis with 3412 cycles, classified into 7 age groups, namely women aged: 30 years; 30 - 35 years; 36 - 37 years; 38 years old; 39 years old; 40 - 44 years; and 45 years. For women aged $40-44$ years, the ET success rate was $85.9 \%$ ( 287 of 334 cycles), while for women aged $\geq 45$ years, the ET success rate was only $50 \%$ (3 out of 6 cycles). This study is different from the previous study because there is a difference in the number of subjects, which affect ET success but not significantly. In addition, there are other factors that affect EF success, which was not studied.

\section{The effect of endometriosis on ET success in IVF}

The results of this study showed that the existence of a history of endometriosis in the mother greatly affects the ET success, which was statistically significant $(p=$ 0.017). The ET success in mothers with a history of endometriosis was only $35.3 \%$, while $71.3 \%$ of mothers without a history of endometriosis were successful in embryo transfer. This is in line with the previous studies.

A retrospective cohort study by González-Comadran et al. (2017) stated a statistically high embryo transfer failure rate in the group of women with endometriosis compared to the control group $(\mathrm{p}=$ 0.005). In the study by González-Comadran et al. (2017), the control group referred to in the study are women who have tubal factor infertility, endocrine disorders, or idiopathic infertility. The embryo transfer failure rate in the endometriosis group was $3.94 \%$, while in the control group, it was
2.95\%. However, it was not clinically significant because there was only a $0.99 \%$ difference between the control and endometriosis groups.

A study by Singh et al. (2014) also showed that the embryo transfer failure rate in women with endometriosis was higher (15.4\%) compared to women with a history of tubal factor infertility, but it was not statistically significant $(\mathrm{p}=0.084)$. The unsuccessful embryo transfer in the study of Singh et al. (2014) is caused by the absence of oocytes during the oocyte uptake phase; oocytes fail to develop or fail to be fertilized. This and previous studies also reinforce the theory that endometriosis has a negative effect on IVF.

\section{The effect of PCOS on the ET success in IVF}

This study stated that the presence of a history of PCOS in the mother affected the ET success, but it was not statistically significant $(p=0.257)$. In this study, the ET success rate in women with a PCOS history was higher than those without this history $(\mathrm{PCOS}=87.5 \%$, non-PCOS $=62.1 \%)$. Mothers with a history of PCOS were 2.5 times more likely to succeed at embryo transfer than those without $(\mathrm{OR}=2.51 ; 95 \%$ $\mathrm{CI}=0.51-12.31)$.

This contrasts with previous studies, where a study conducted by Zhong et al. (2012) in China with 990 cycles showed that PCOS has a negative effect on the outcome of IVF. PCOS causes the IVF cycle to fail. In the study conducted by Zhong et al. (2012), women with a history of PCOS or ovulatory PCO had a cycle failure rate greater than normal $(\mathrm{p}<0.05)$. Zhong classified the IVF cycle's failure into three groups, where one group was due to failure in oocyte retrieval, abnormalities in fertilization or division, poor embryo quality, and endometrial factors.

The results of a study conducted by 
Kodama et al. (1995), who studied 501 cycles, stated that there was a significantly higher incidence of failed embryo transfer in women with PCOS (22\% versus $8 \%, \mathrm{p}$ $<0.01)$ compared with the control group (tubal factor infertility, endometriosis, idiopathic). The cause of failure is due to failure in the development of oocytes and fertilization.

There are differences in the study results due to other factors that affect the ET success, which were not studied. The presence of ovarian stimulation with drugs also results in optimal IVF results in women with PCOS. One of them is the administration of clomiphene citrate, which is one of the treatments for PCOS but is also used in the IVF procedure. About $75 \%$ of women with PCOS will successfully ovulate induced by clomiphene citrate. The more the dose of clomiphene citrate, the ovulation rate will increase (Langdon, 2017). Metformin is also useful in women with PCOS who are resistant to clomiphene citrate. A study conducted by Stadtmauer et al. (2001), administering metformin doses of 1000-1500 mg per day can increase the outcome of IVF.

The difference in the number of subjects in this study with the previous one causes this study not significantly to affect embryo transfer success. Besides, differences in the method of diagnosis can also affect the results of the study. There are several PCOS diagnostic criteria that can be used, including 1990 NIH criteria; Rotterdam 2003; Androgen Excess - PCOS Society 2006; and NIH 2012 / International PCOS Guidelines 2018 (Wolf et al., 2018).

\section{The effect of obesity on ET success in IVF}

The results shown in this study were obesity did not significantly affect the success of embryo transfer $(\mathrm{p}=0.277)$. This study also showed that obese had a 1.65 times chance of successful embryo transfer than non-obese $(\mathrm{OR}=1.65 ; 95 \% \mathrm{CI}=0.67-$ 4.10).

A retrospective study conducted by Dokras et al. (2006) in 1293 women aged less than 38 years showed BMI $\geq 40$ influenced the success rate of embryo transfer statistically significant compared to BMI $<25$ ( $\mathrm{p}<0.001$ ). The success of embryo transfer in women with $\mathrm{BMI} \geq 40$ was only $69.62 \%$. However, there was an increase in the success of embryo transfer in 2 groups, namely the group with BMI 25 - 29.9 and BMI 30 - 39.9 compared with BMI <25 (BMI <25: 84.33\%; BMI 25 - 29.9: 85.42\%; BMI 30 - 39.9: 86.86\%).

A study conducted by Sathya et al. (2010) showed that increased BMI in women did not affect IVF results, such as oocyte quality, fertilization rate, embryo cleavage rate, quality embryo quality, and clinical pregnancy rate. This is also shown by a study conducted by Ozekinci et al. (2015) where IVF outcomes such as the number of oocytes retrieved, the level of mature oocytes, transferable embryos, fertilized oocytes, and the rate of cycle cancellation were not significantly different in the normal BMI, overweight, or obese groups (all $\mathrm{p}>0.05$ ). This could explain the results of this study, where obesity did not significantly affect ET success.

This study has a significant difference from previous studies due to differences in the number of research subjects. Besides, it can also be caused by factors such as age. Previous studies examined women with an age range of fewer than 38 years, whereas this study did not use a specific age range.

This study concludes that the prevalence of ET success in IVF from January 2014 to November 2019 at Sekar Fertility Clinic, Dr. Moewardi hospital is $65.77 \%$ (73 of 111 cycles). Only a history of endometriosis can affect the ET success statistically 
significant $(\mathrm{aOR}=0.25 ; 95 \% \mathrm{CI}=0.08$ to $0.78 ; \mathrm{p}=0.017)$.

\section{AUTHOR CONTRIBUTION}

Atthahira Amalia Hafiizha conducted data collection, categorized data, analyzed, and wrote a script. Uki Retno Budihastuti gave theoretical suggestions about the effect of age, endometriosis, PCOS, and obesity in mothers on the ET success in IVF. Bhisma Murti assisted in the data analysis and interpretation of study results.

\section{CONFLICT OF INTEREST}

There is no conflict and interest in this study.

\section{FUNDING AND SPONSORSHIP}

This study used the authors' funds.

\section{ACKNOWLEDGEMENT}

The author would like to express their gratitude to Prof. Dr. Soetrisno, dr., Sp.OG (K) provided guidance, suggestions, and constructive criticism in this study and Dr. Moewardi hospital, who permitted this study to be carried out.

\section{REFERENCE}

Dokras A, Baredziak L, Blaine J, Syrop C, VanVoorhis BJ, Sparks A (2006). Obstetric outcomes after in vitro fertilization in obese and morbidly obese women. Obstet Gynecol. 108(1): 6169. doi: 10.1097/01.AOG.0000219768.08249.b6.

González-Comadran M, Schwarz JE, Zegers-Hochschild F, Souza MDCB, Carreras R, Checa MA (2017). The impact of endometriosis on the outcome of Assisted Reproductive Technology. Reprod Biol Endocrinol. 15(8): 1-7. doi: 10.1186/s12958-016-0217-2.

Hourvitz A, Machtinger R, Maman E, Baum M, Dor J, Levron J (2009). Assisted reproduction in women over 40 years of age: How old is too old? Reprod Biomed Online. 19(4): 599-603. doi: 10.1016/j.rbmo.2009.04.002.

Ji J, Liu Y, Tong XH, Luo L, Ma J, Chen $Z$ (2013). The optimum number of oocytes in IVF treatment: an analysis of 2455 cycles in China. Hum Reprod. 28(10): 2728-2734. doi:10.1093/humrep/det3o3.

Kodama H, Fukuda J, Karube H, Matsui T, Shimizu Y (1995). High incidence of embryo transfer cancellations in patients with polycystic ovarian syndrome. Hum Reprod. 10(8): 19621967.

Langdon F, Pontre J, Hart RJ (2017). Darwish A. Fertility treatment for women with PCOS. Testes and Ovaries: Functional and clinical differences and similarities. IntechOpen. doi: 10.5772/intechopen.71188.

Niederberger C, Pellicer A, Cohen J, Gardner DK, Palermo GD, O'Neill CL, Chow S, et al. (2018). Forty Years of IVF. Fertil Steril. 110(2): 185-324. doi: 10.1097/01.JU.0000553048.13430.38 .

Ozekinci M, Seven A, Olgan S, Sakinci M, Keskin U, Akar ME, Ceyhan ST, et al. (2015). Does obesity have detrimental effects on IVF treatment outcomes? BMC Womens Health. 15(61): 1-7. doi: 10.1186/s12905-015-0223-0.

PERFITRI (2017). IVF Registry. Retrieved from https://www.perfitri.org/ivf- registry/.

Prawirohardjo S (2014). Ilmu Kandungan. Edisi ketiga. Jakarta: PT Bina Pustaka Sarwono Prawirohardjo.

Sathya A, Balasubramanyam S, Gupta S, Verma $T$ (2010). Effect of body mass index on in vitro fertilization outcomes in women. J Hum Reprod Sci. 3(3): 135-138. doi: 10.4103/0974- 
Hafiizha et al./ the Success of Embryo Transfer on In Vitro Fertilization

1208.74155.

Singh N, Lata K, Naha M, Malhotra N, Tiwari A, Vanamail P (2014). Effect of endometriosis on implantation rates compared to tubal factor in fresh non donor in vitro fertilization cycles. $\mathrm{J}$ Hum Reprod Sci. 7(2): 143- 147. doi: 10.4103/o974-1208.138874.

Sirmans SM, Pate KA (2014). Epidemiology, diagnosis, and management of polycystic ovary syndrome. Clin Epidemiol. 6(1): 1-13. doi: 10.2147/clep.s37559 .

Stadtmauer LA, Toma SK, Riehl RM, Talbert LM (2001). Metformin treatment of patients with polycystic ovary syndrome undergoing in vitro fertilization improves outcomes and is associated with modulation of the insulin-like growth factors. Fertil Steril. 75(3): 505-509. doi: 10.1016/So015-0282(oo)01766-o.

Tan TY, Lau MSK, Loh SF, Tan HH (2014). Female ageing and reproductive outcome in assisted reproduction cycles. Singapore Med J. 55(6): 305-309. doi: 10.11622/smedj.2014081.

Wolf WM, Wattick RA, Kinkade ON, Olfert
MD (2018). Geographical prevalence of polycystic ovary syndrome as determined by region and race/ethnicity. Int $\mathrm{J}$ Environ Res Public Health. 15(11): 1-13. doi: 10.3390/ijerph15112589 .

Zegers-Hochschild F, Adamson GD, de Mouzon J, Ishihara O, Mansour R, Nygren K, Sullivan E, et al. (2009). International committee for monitoring assisted reproductive technology (ICMART) and the World Health Organization (WHO) revised glossary of ART terminology, 2009. Fertil Steril. 24(11): 2683-2687. doi: 10.1016/j.fertnstert.2009.09.009.

Zhong YP, Ying Y, Wu HT, Zhou CQ, Xu YW, Wang Q, Li J, et al. (2012). Comparison of endocrine profile and in vitro fertilization outcome in patients with PCOS, ovulatory PCO, or normal ovaries. Int J Endocrinol. 2012: 1-6. doi: 10.1155/2012/492803. 